\title{
Active Power Filter for Power Quality Improvement in Micro Grid
}

\author{
Hao Jing \\ School of North China Electric Power University, Beijing 102206, China \\ jinghao98765@163.com
}

Keywords:Active Power Filter, distributed power, power quality.

\begin{abstract}
Distributed generation has extensive economic benefit and social benefit, but it costs too high to connect to the grid directly and it is too difficult to control. Therefore, the matching of power electronic equipment interface is very important. In this paper, we use a shunt active power filter model to deal with the Micro Grid operation. It makes a good compensation effect, improving the system's power quality. The simulation and experimental results verify the correctness of the theory analysis.
\end{abstract}

\section{Introduction}

With the continuous increase of the global environmental pressure, distributed generation has aroused widespread attention at home and abroad. Distributed generation is energy saving and environmental protection. It has high reliability and economic price, which can also solve the problem of remote area power supplement. But in the actual operation of micro grid, distributed power supply and cannot fully meet the needs of power quality system. Through the inverter incorporated into the grid, it will cause voltage fluctuation and frequency deviation, resulting in harmonic content increased, the phase-locked difficulties, affecting the normal work.

Uncontrollable diode rectifier converter has been widely used in switching power supply. But this kind of converter will inject large amount of harmonic current to the grid, which is increasingly becoming an important factor affecting the quality of power supply system. The traditional harmonic suppression method has been unable to meet the modern electric power demand.At present, in contrast, active power filter, as a main method to compensate the nonlinear load harmonic, has the very big superiority.It can accurately compensate reactive power and harmonic. With the wide application of power electronic devices, APF gradually replace traditional passive filter, becoming the important means of harmonic suppression.Therefore, using APF to control harmonic problems of Micro Grid mode has important significance to improve the Micro Grid harmonic problems and the power quality.

\section{Basic working principle of APF}

Due to the different access to grid, APF can be divided into series active power filter and shunt active power filter. First of all, APF detects a current harmonics and the size of reactive power current. Then generates compensating current with the same size opposite phase, the current after filtered only contains fundamental active sine wave.

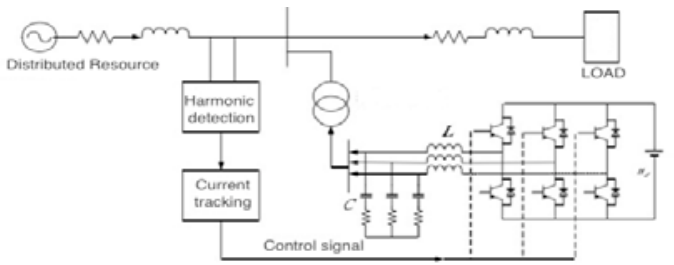

Fig.1-1 Micro Grid diagram of APF

Assuming that $U_{c}$ is the output voltage of active power filter inverter; $U_{S}$ is the system voltage; $L$ is the equivalent connecting inductance; $i_{c}$ is the compensation current.

Then, there is;

$U_{c} \approx U_{s}+L \frac{d i_{c}}{d t}(1)$ 
Let $\mathrm{U}_{\mathrm{dc}}$ be a DC capacitor voltage of voltage source inverter. $\mathrm{K}_{\mathrm{m}}$ Is a function associated with the control method, it has the following relationship:

$U_{c}=K_{m} U_{d c}$

As can be seen from the formula, decreasing the inductance $\mathrm{L}$ and improving the DC side inverter capacitor voltage $\mathrm{U}_{\mathrm{dc}}$ can enhance the current tracking ability.

\section{Micro Grid harmonic suppression of APF}

\subsection{The $i_{p}-i_{q}$ Method}

As a method based on instantaneous reactive power theory to detect harmonic rapidly, it meets the rapid and real-time detection and is widely used in three-phase circuit reactive power and harmonic current detection. As long as we determined the three-phase voltage and current in two-phase, another item is fixed. Therefore, the three-phase voltage and current signals can be alternating to the orthogonal coordinate system. $\mathrm{i}_{\mathrm{p}}-\mathrm{i}_{\mathrm{q}}$ Method uses the way of phase locked loop, and introduce reference signal of voltage. It avoids the influence of voltage distortion. At the same time, for harmonic compensation, the sinusoidal signal phase deviation caused by asymmetric grid voltage is not affected.

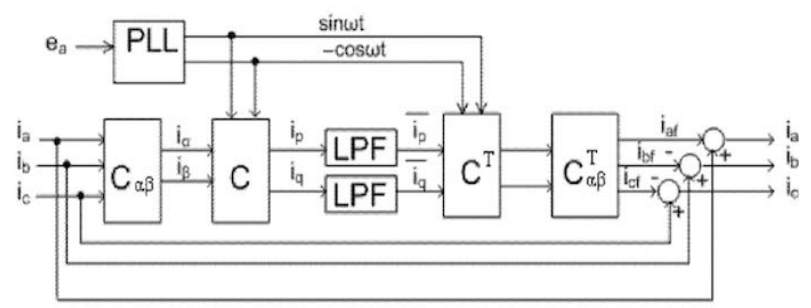

Fig.3-1 The $\mathrm{i}_{\mathrm{p}}-\mathrm{i}_{\mathrm{q}}$ Method of harmonic detection principle diagram

Among them:

$$
\begin{aligned}
& C=\left[\begin{array}{cc}
\sin w t & -\cos w t \\
-\cos w t & -\sin w t
\end{array}\right](3) \\
& {\left[\begin{array}{l}
\mathrm{i}_{\mathrm{p}} \\
\mathrm{i}_{\mathrm{q}}
\end{array}\right]=C\left[\begin{array}{l}
\mathrm{i}_{\alpha} \\
\mathrm{i}_{\beta}
\end{array}\right]=\mathrm{CC}_{\alpha \beta}\left[\begin{array}{l}
\mathrm{i}_{\mathrm{a}} \\
\mathrm{i}_{\mathrm{b}} \\
\mathrm{i}_{\mathrm{c}}
\end{array}\right]}
\end{aligned}
$$

The $i_{p}-i_{q}$ Method does not need to detect the three-phase voltage of the grid. It only need phase of a phase voltage to calculate the sine and cosine signal. Therefore, voltage unbalance resulting of sine and pre deviation does not affect the harmonic compensation.

\subsection{Tracking current control method of APF}

Based on the harmonic current detection in the last section, according to the difference of harmonic current and compensation current, APF obtains the PWM pulse signals with a certain control method to control the inverter output.

Current tracking PMW control mode mainly has three kinds of methods: Hysteresis comparison control, triangular wave comparison control and instantaneous value comparison control. Among them, by using hysteresis comparison, the tracking effect is mainly decided by hysteresis width and switchingfrequency of switching element, also is the turn-on angle of thyristor, which make the compensation current track the detected changes of reference current. The difference enter controller, compared with the width of ring settings, changing the main circuit of inverter and branch. Because of its simple hardware circuit, quick current response, it is widely used at present.

Adopts triangular wavecomparison control, the switching frequency is fixed, but the load the current rising will cause the current not on the track, leading to the formation of burrs.

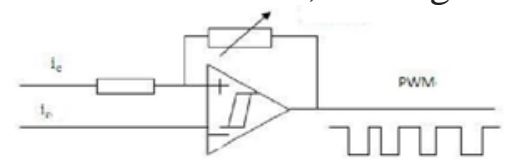

Fig.3-2 Hysteresis comparison control 


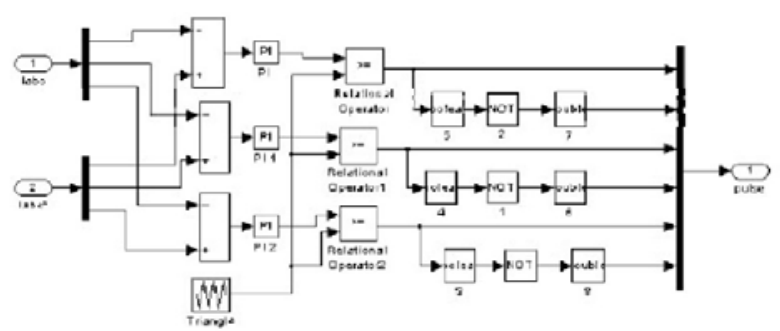

\subsection{Deadbeat current control}

Fig.3-3 Triangular wave comparison control

Deadbeat control is mainly suitable for current waveform distortion problems brought by nonlinear load. It need large amount of calculation. But the fast response speed can improve the dynamic response performance of PWM inverter, which is suitable as a control method of APF.

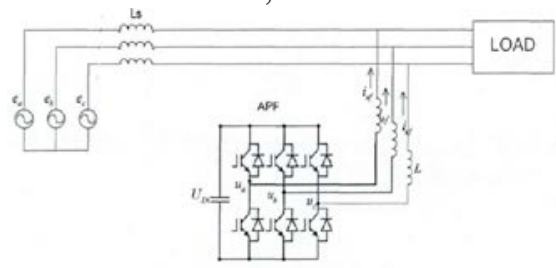

Fig.3-4 Deadbeat current control

Loop voltage equation:

$$
\left\{\begin{array}{l}
L \frac{d i_{a f}}{d t}+e_{a}=U_{a} \\
L \frac{d i_{b f}}{d t}+e_{b}=U_{b}(5) \\
L \frac{d i_{c f}}{d t}+e_{c}=U_{c}
\end{array}\right.
$$

The three-phase coordinate transforms to $\alpha \beta 0$ coordinate decoupling:

$$
\left\{\begin{array}{l}
L \frac{d i_{a f}}{d t}=U_{a}-e_{a} \\
L \frac{d i_{b f}}{d t}=U_{b}-e_{b}(6) \\
L \frac{d i_{c f}}{d t}=U_{c}-e_{c}
\end{array}\right.
$$

Choose $\mathrm{T}$ as the sampling period and discrete (6). The final APF deadbeat control equations:

$$
\left\{\begin{array}{l}
U_{\alpha}(k+1)=L \frac{i_{\alpha f}(K+1)-i_{\alpha f}(K)}{T}-U_{\alpha}(k)+2 e_{a}(K) \\
U_{\beta}(k+1)=L \frac{i_{\beta f}(K+1)-i_{\beta f}(K)}{T}-U_{\beta}(k)+2 e_{\beta}(K)(7) \\
U_{0}(k+1)=L \frac{i_{0 f}(K+1)-i_{0 f}(K)}{T}-U_{0}(k)+2 e_{0}(K)
\end{array}\right.
$$

By the deadbeat theory, change the reference current tracking to reference voltage tracking, the current tracking is faster, more accurate and more efficient.

\section{Simulation and analysis}

APF is mainly composed of detection circuit, current tracking drive current module and the main module. According to the external characteristics of distributed power supply conduct the simplified equivalent, that all distributed power supply is connected to the same DC bus, which should fit the needs of the three-phase alternating current through the inverter

Distributed power through the inverter convert to alternating current. Firstly it goes through the LC to filter out the higher harmonics, and then through the APF precise filter on harmonic. In island operation, distributed power only internal to Micro Grid load power supply. 


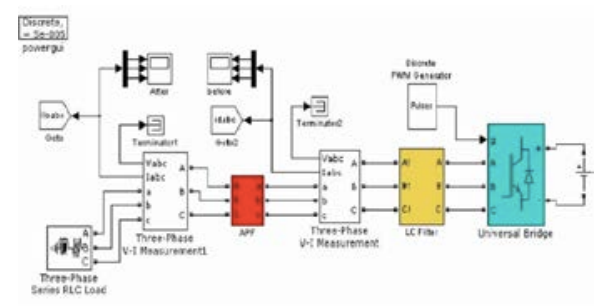

Fig.4-1 Micro Grid operation simulation structure

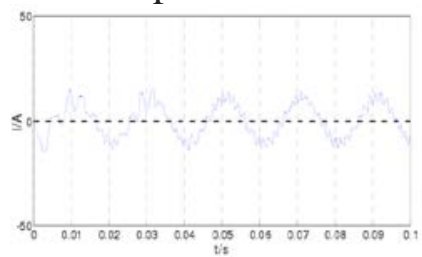

Fig. 4-2 Export current of distributed power

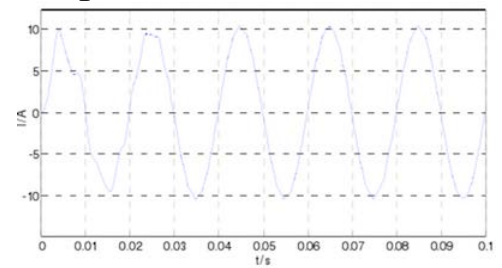

Fig. 4-3 Export current of APF

As the above chart shows, this paper adopts the method of harmonic detection and tracking control. The load current harmonics after compensation is effectively filter. Micro Grid power quality is improved effectively.

\section{Summary}

This article analyzes the distributed generation system and the basic principle of micro operation, do research on controlling strategy of Micro Grid, and establish a simulation model of the instantaneous reactive power of shunt active power filter. The simulation analyzed by Matlab/Simulink proves that APF can suppress the harmonic and improve the micro grid-power quality, which has high practical value.

\section{Reference}

[1] Wang Qun,Yao Weizheng, Liu Jinjun,et al.Harmonic sources and compensation characteristics of active power filters[J].Proceedings of the CSEE,2001,21(2):16-20.

[2] Wu Xiaomei, Li Songdong, Wen Fushuan. Application of instantaneous reactive power thory in power quality control of distribution network[J]. Power system protection and control, 2009, 37(10): 79-82.

[3] Wei Xueliang,Dai Ke,Fang Xin,et al.Performance analysis and improvement of output for three phase shunt active power filter[J].Proceedings of the CSEE,2007, 27(28):110-119.

[4] Li Cheng,Zou Yunping.Active power filter to suppress harmonic caused by nonlinear load[J].Automation of Electric Power Systems,2003,27(20):29-33

[5] LE Jian,JIANG Qirong. The analysis of hysteresis current control strategy of three-phase four-wire APF based on the unified math- ematic model[J]. Proceeding of the CSEE,2007,27 ( 10$)$ : $83-91$.

[6] LI Yumei,MA Weiming. Application of deadbeat control in series active power filter[J]. Automation of Electric Power Systems, 2001, 25( 4) : 28 - 30.

[7] Georgakis D,Papathanassiou S,Hatziargyriou N,et al. Op-eration of a prototype microgrid system based on micro- sources quipped with fast-acting power electronics interfaces [C]. IEEE 35th Annual Power Electronics Specialists. 